\title{
Fotoğraf Sanatında Kusur Kavramının Bilinçli Kusur Bağlamında Yeniden Sunumu
}

\author{
Gökhan BİRİNCI**
}

Birinci, G. (2020). Fotoğraf Sanatında Kusur Kavramının Bilinçli Kusur Bağlamında Yeniden Sunumu. YEDİ, 23, 35-43, doi: 10.17484/yedi.602421

Araştırma Makale / Research Article

Özet

Giderek artan teknolojik gelişmeler bir yandan yaşamımızın ayrılmaz bir parçası haline gelmiş diğer yandan makinelerle olan etkileşim ve iletişim kazaların belli oranda artmasına sebep olmuştur. Bir sistem ya da işlemdeki arızadan kaynaklanan hata ve kusurlar bir yandan bilim insanlarını meşgul ederken diğer yandan bu kazalar, sanat dünyasında kimi zaman önemli bir bağlam olarak değerlendirilmektedir. Herhangi bir sanatsal ortam içindeki aksaklık ya da rastlantısallık kasıtlı ya da kasıtsız olsun izleyicide bir izlenim oluşturabilir. Kaza, kusur ya da rastlantı sonucu ortaya çıkan ancak sonraları bilinçli kusur haline dönüştürülen sanat yapıtı ile izleyici arasında düşünsel bir bağ oluşturulmuştur. Teknik, optik ve kimyası gereği ortaya çıkan bu yeni arayışlar, fotoğraf estetiği ve kuramı bağlamında sanatçılara bir yandan görüntü tasviri sağlarken diğer yandan izleyiciyi bu yeni vizyonu algılama ve sorgulamaya zorlamaktadır. Bu çalışmada kaza sonucu oluşan kusurlu görüntülerin Andre Kertezs, Man Ray, Robert Capa, Dafna Talmor, Aliki Braine, Alison Rossiter, Charles Grogg, Lisa Folino, David Virgin ve Rose Menkman’ın çalışmalarına nasıl yansıdığı irdelenecek ve yorumlanacaktır.

Anahtar Sözcükler: Kaza, kusurlu fotoğraf, rastlantı, analog fotoğraf, dijital fotoğraf.

\section{Representation of Defect Concept in the Context of Conscious Defect in Photographic Art}

\section{Abstract}

On the one hand, increasing technological developments have become an inseparable part of our lives, on the other hand the interaction and communication with the machines has caused increasing accidents. While errors and defects resulting from failure of a system or process are keeping scientists busy, sometimes, these accidents might be considered as an important context in the art world. Any disruption or randomness in any artistic setting, whether intentional or unintentional, can create an impression on the viewer. An intellectual connection established between the work of art and the audience as a result of accident, defect or coincidence, was later transformed into a conscious defect. In the context of photography aesthetics and theory, these new researches, resulting from the technical, chemical and optical processes provide image depictions to artist, moreover force the viewer to perceive and question this new vision. In this study, it will be investigated and interpreted how the accidental defective images are reflected in the work of Andre Kertezs, Man Ray, Robert Capa, Dafna Talmor, Alliki Braine, Alison Rossiter, Charles Grogg, Lisa Folino, David Virgin and Rose Menkman.

Keywords: Accident, defective photograph, coincidence, analog photography, digital photography. 


\section{Giriş}

19. yüzyılın başlarından bu yana her yeni teknolojik gelişme görüntü üretim sürecinin belli oranda bozulmasına neden olmuştur. Hem bilim hem de sanat insanlarının hatta amatör fotoğrafçıların kaza ve kusur sonucu ürettikleri fotoğraflar görüntü kirliliği yaratmaktadır. Ancak yine de bu kaza sonucu ortaya çıkan kusurlu görüntülerin çok geçmeden olumlu yönleri de görülmeye başlamıştır.

Kusurlu olarak adlandırılan görüntüler sadece 19.yüzyıl fotoğraf sürecinde değil aynı zamanda çağdaş sanatın konusu olmuş ve yeni estetik ve söylemlerin dillendirildiği bağlamlara dönüşmüşlerdir. Bir yandan teknik, optik ve kimyasal görüntü tasvirinden diğer yandan dijital işlem tekniklerinden kaynaklanan kaza ve kusurlu görüntülerin estetik ve kuramsal boyutlarını tartışmak bu çalışmanın temel unsurudur.

Fotoğraf tarihi boyunca hem analog hem de dijital teknoloji sonucu oluşan kusur ya da rastlantısallıklar fotoğraf sanatına yeni deneysel yaklaşımlar sunmaktadır. Ayrıca bu kazaları yeni bir estetik anlayış ile özümseyen fotoğraf sanatçısının bu yöntemleri nasıl ele aldığı, teknik, kimya ve optik gereği hiçbir beceri ve yorum getirmeyen sıradan ve hatalı görüntülerin strateji geliştirme ve yeni vizyon oluşturma bağlamında sanatçıların nereden esinlendikleri de önemlidir.

Teknolojik bir araç (medium) olarak fotoğraf, optik ve kimyasal doğası nedeniyle kaza veya kusurlara neden olabilecek nitelliklere sahiptir. Ancak bütün olumsuzluğa rağmen bu kazalar olumlu ve sürpriz diyebileceğimiz rastlantılara da sebep olmaktadır.

İngiliz siyasetçi, aristokrat ve yazar Horace Walpole'un türettiği bir sözcük olan aramazken bulunan, mutlu tesadüf ya da mutlu kaza olarak nitelendirilen 'Serendipity’ (serendipçe), bir yandan alternatif fotoğraf üretim biçimleri sunarken diğer yandan fotoğraf estetiği ve kuramında da önemli bir kavram olarak karşımıza çıkmaktadır.

Fotoğraf ortamlarında kaza ve rastlantısallıklar sonucu ortaya çıkan ve bir döneme ilham veren kusurlu görüntüler, bugün çağdaş sanatın yeni görsel anlam üretimi bağlamında değerlendirilmektedir.

Bu çalışmada, August Strindberg, Andre Kertezs, Man Ray, Robert Capa, Dafna Talmor,Aliki Braine, Alison Rossiter, Charles Grogg, Lisa Folino, David Virgin ve Rose Menkman gibi sanatçıların kaza estetiğini geliştirerek öngörülmeyen kusurlu görüntüleri çalışmalarına nasıl yansıttıkları irdelenecek ve yorumlanacaktır.

\section{Analog Çağda Kusurlu Fotoğraf}

Aslında şair, oyun yazarı olan Strindberg, teknolojiye olan ilgisinden dolayı fotoğrafa yönelmiş ve bu alanda birçok deneysel çalışmalar gerçekleştirmiştir. 1880'li yıllarda Strindberg, gece gökyüzünün altında doğrudan geliştirici sıvıyla dolu bir kabın içine duyarlı levhalar yerleştirerek kamerasız görüntüler elde etmiş ve doğa bilimlerinin fotoğraftaki etkisini araştırmıştır. 'Calestograph' olarak adlandırılan görüntüler, buharlaşmış, kıvrılmış yıldızlı alanlar ve bulutsu izlerden oluşmakta, nemli havanın, tozun, ışığa duyarlı levhalar üzerindeki kontrolsüz kimyasal sapmaların etkileşimleri bilime bilinmeyen bir gerçeği kaydetme olanağı sağlamıştır. Duyarlı levhalar üzerinde kar kristallerinin sonsuz küçüklükten sonsuz büyüklüğe doğru hareket eden güneşi, ayı, yıldız ve bulutları fotogramla eş anlam olan bir yöntemle fotoğrafik deneyler yapmıştır (Bakınız Şekil 1).

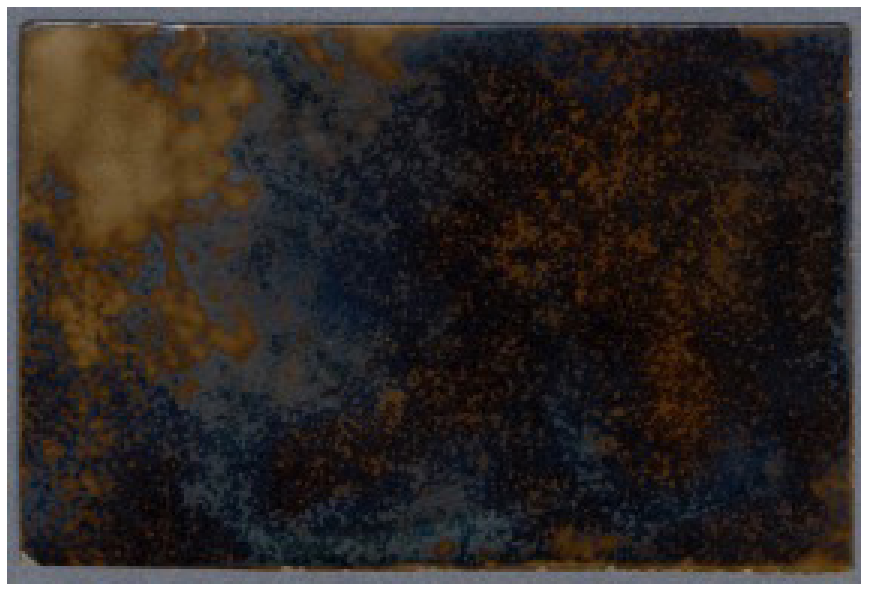

Şekil 1. Celestograph, A. Strindberg, 1890

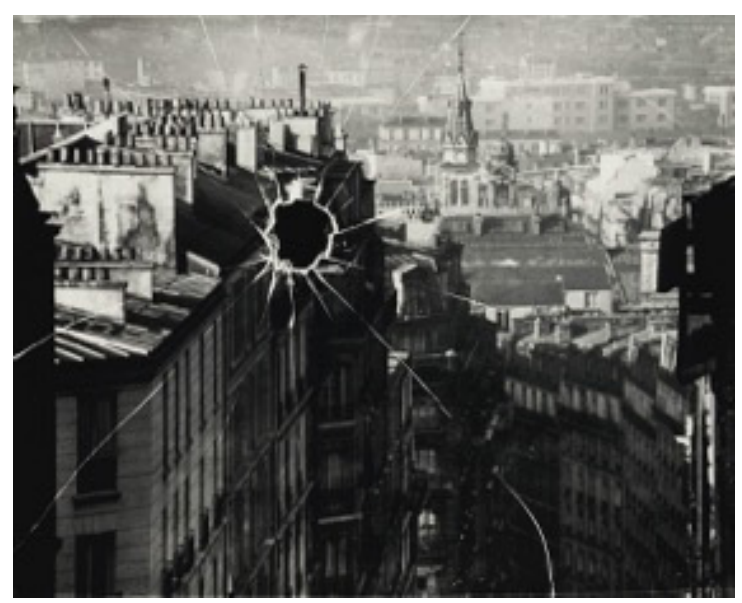

Şekil 2. Broken Plate, A. Kertesz, 1929 
Steidl'e göre (2011, s. 11):

Strindberg, şansın yaratıcı süreçte hayati bir rol oynadığına inanmış ve bu kavramı resim, fotoğraf ve sanatsal yazılarında araştırmıştır. 19. yüzyıl fotoğrafçılığının bir üretim biçimi olan fotogram tekniği ile dünyanın gizli veya görünmeyen olaylarını ortaya çıkarmış ve bu tekniğin, insan gözünün yerine geçecek bir tür olarak kabul görülmesine öncülük etmiştir. Fotogramın dokunsal nitelikleri, on dokuzuncu yüzyılın bilim ve felsefi düşüncesinde merkezi bir rol üstlenmiş ve bu da fotogramın tekniğini sanatsal bir ilke olarak şekillendirmiştir.

Bu söylemi ile bu tür fotoğrafik denemelerin günümüz çağdaş fotoğraf sanatında da ilgi duyulmasına neden olmuştur.

Strindberg'in 'Celestograph'ların görünümleri soyut ve kusurlu olabilir ancak bu denemeler yine de fotoğrafın mimetik dokümantasyon kapasitesine ve gerçek bir nesneyi temsil etme potansiyeline atıfta bulunmaktadır. Bu nedenle Strindberg'in fotogramları moderniteye ve 1920'lerin avangard hareketin yeni algı teorisine doğru atılmış önemli bir adım olarak görülmüştür.

Giderek artan teknoloji dünyamızda kaza sonucu oluşan aksaklık ve kusurlar yaşamımızın ayrılmaz bir parçası haline gelmiştir. Bir sistem ya da işlemdeki arızadan kaynaklanan hata ve kusurlar bir yandan bilim insanlarını meşgul ederken diğer yandan bu kazalar, sanat dünyasında kimi zaman önemli bir bağlam olarak değerlendirilmektedir. Herhangi bir sanatsal ortam içindeki aksaklık ya da rastlantısallık kasıtlı ya da kasıtsız olsun izleyicide bir izlenim oluşturabilir. Kaza, kusur ya da rastlantı sonucu ortaya çıkan ancak sonraları bilinçli kusur haline dönüştürülen sanat yapıtı ile izleyici arasında düşünsel bir bağ oluşturulmuştur.

Paul Virilio, hız ve kaza ile ilgili teorisinde başarısızlığın bir kaza olduğunu ancak bunun bazen olumlu sonuçlar doğurabileceğini ve devamında sanat dünyasında da bu tür kazaların yeni bir estetik anlayışı ortaya çıkardığını belirtmiştir. Virilio'nun (2016, s. 95) ifade ettiği gibi:

Gerçekte devrim niteliğinde bir sanat, bir heykel, bir film, bir konsept icat ettiğinizde, ya da ilk gemiyle sefere çıktığınızda, ilk uçağı uçurduğunuzda veya ilk uzay kapsülünü fırlattığınızda çarpışmayı icat etmiş olursunuz. Duchamp, ‘Büyük Cam'ı meydana getirdiğinde bir icatta bulunur ve aynı anda bir kaza meydana gelir. Bu kaza nedir? Duchamp'ın kazası nedir? diye sorar ve ekler ‘Büyük Cam' çatlamıştır.
Bu bir sanat kazasıdır; tıpkı Andre Kertesz’in 1929 yılında gerçekleştirdiği 'Kırık Levha' adlı çalışması gibi.

Macar asıllı Amerikalı fotoğrafçı Kertesz, 1929 yılında Paris'in fotoğraflarını çekmiştir. Paris manzarası olarak çekilen fotoğrafta Notre Dame ve çevresi görülmektedir. Başlangıçta bu bir Paris manzarasıdır. Ancak Kertesz, 1931 yılında Amerika'dan Paris'e geri döndüğünde cam negatiflerin kırıldığını görmüştür. Kertesz bu çalışmaya farklı bir isim vermiştir: Kırık Levha 'Broken Plate’ . Bu çalışma Paris’i ve aynı zamanda fotoğraf görüntüsünü kaydeden malzemeyi eş zamanlı olarak göstermektedir. Kırık Levha, izleyicinin bakışlarını şehrin fotoğrafına, fotoğrafı oluşturan malzemeye ve onu temsil eden cam negatifi oluşturan çatlaklara yöneltmektedir (Bakınız Şekil 2).

Kertesz, yıkım ve bozulma sonucu ortaya çıkan bu kusurlu görüntü ile bize farklı bir fotoğraf kazası sunmaktadır. Paris şehrinin fotoğrafı tesadüfî olarak fotoğraf malzemesinin kendi varlığından kaynaklanan bir kaza sonucu olarak ortaya çıkmıştır. Bu kaza belgesel fotoğrafa ve onun referanslarına bir yandan gerçeklik etkisi katarken diğer yandan temsil edilen sahnenin politik ve psikolojik göstergeleri kırık cam katmanları ile izleyiciye sunulmaktadır.

Friedlander (2008, s. 157) bu kaza ile ilgili olarak "temsil edilen sahnenin Barthes'in belirttiği gibi gerçeklik etkisi içinde geliştirilen estetik gerçeklik ile referans gerçeklik arasındaki ayrımdan yola çıkarak Kertesz'in iki gerçeklik biçimini bir araya getirmekte zorlandığını” belirtir. Kertesz’in 'Kırık Levha' da izleyicinin bakış açılarını siyah katmanlara yöneltmektedir. Fotoğraftaki büyük boşluklar izleyicide motif algısı yaratmaktadır. Sanatçı burada yıkım ve bozulma olayını kırık cam negatif üzerinden gerçek kazayı sergilemektedir.

20 yüzyılın başlarında Man Ray ve asistanı Lee Miller’ın bulduğu ‘solarizasyon' tekniği, Martin (1982, s. 12)'in ifade ettiği gibi “Man Ray bu tekniği tamamen şans eseri icat ettiğinde bu teknik onunla birlikte anılır oldu ve rayogram tekniği ile birlikte en sevdiği temalardan biri haline geldi. Ray, bu tekniği geleceğe doğru atılmış büyük bir adım olarak gördü ve rayogram çalışmalarını mümkün olduğunca sık sundu”. Man Ray hem rayogram hem de solarizasyon tekniğinde ışığın bazen beklenmedik oyunlarını sunarken bize aynı zamanda bu tekniğin bir resim bilgisi olarak ve aynı zamanda karşı koyulmaz bir şekilde geleneksel felsefi rolünü de hatırlatmaktadır. Böylece Man Ray, bu teknikle zaman kavramının maddesel bir karakteristik özelliği olan ışığı bir madde olmaktan çıkarıp estetik bağlamda değerlendirmiştir. 
Sürrealist çalışmaları ile bilinen Man Ray bu tekniği sadece sanatsal çalışmalarında değil, aynı zamanda moda fotoğrafında da uygulamış ve bu konuda öncülük etmiştir. Avangard portre çalışmalarını Vogue ve Vanity Fair gibi moda dergilerinde yayımlamıştır. Bu dergiler için deneysel çalışmalar gerçekleştirmiştir. Başlangıçta Man Ray’ın kaza sonucu olarak ortaya çıkan solarizasyon ve rayogram tekniği, ticari fotoğraftan deneysel sanat eserine ne kadar yakından bağlı olduğunu ortaya koymuştur. 1920-1940 yılları arasında Paul Poiret, Madeleine Vionnet, Jeanne Lanvin, Elsa Schiaparelli gibi Parisli modacılar ile çalışan Man Ray’in Vanity Fair’ de rayogram ve solarizasyon tekniği ile gerçekleştirdiği dört adet fotoğrafı yayımlamıştır (Bakınız Şekil 3).

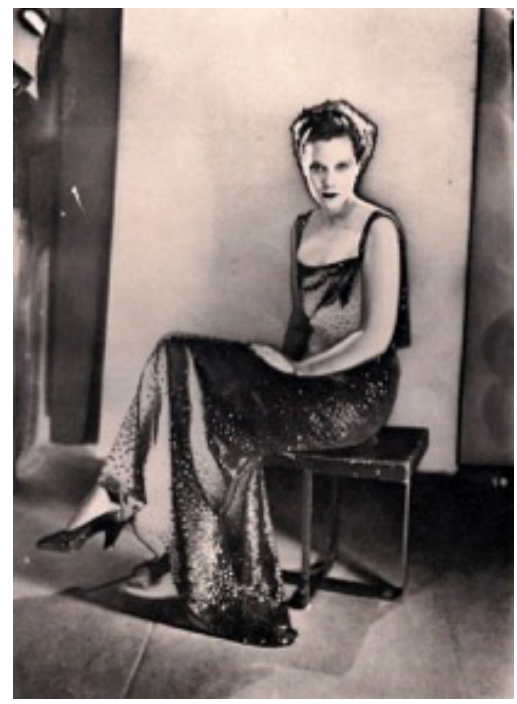

Şekil 3. Partial Solarization, M. Ray, 1935

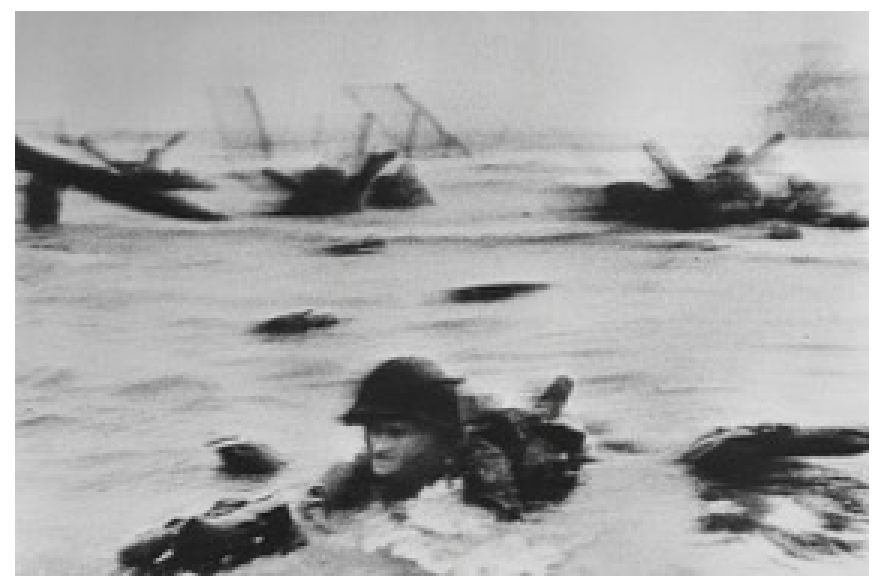

Şekil 4. D-Day, R. Capa, 1944, Normandiya, Fransa
20. yüzyılın ortalarında fotoğraf alanında görülen kusur ve kazalar yalnızca sanat ortamlarında değil tarihe tanıklık eden belge ve arşivleme alanlarında da kendini göstermiştir. Bu kazalardan biri İkinci Dünya Savaşı'nda görülmüştür. Omoha Sahili'ne ilk ve tek fotoğrafçı olarak çıkan Robert Capa'nın ikonik fotoğrafları tarihe benzersiz bir belge sunmaktadır.

Robert Capa'nın fotoğrafik dehasının temel nedeni anlatıya dayanmasıdır. Magnum'un fotoğrafik hikaye anlatım geleneğini yaratan Capa'nın fotoğrafçılığı tamamen orada ve konuya yakın olmakla ilgilidir. Capa, fotoğraf yaşamı boyunca tanık olduğu olayların anlatımını nasıl şekillendireceği ve sunacağı konusunda sürekli risk almıştır.

Normandiya çıkarması sırasında çekilen işgal fotoğrafları karanlık oda asistanın negatifleri istemeden aşırı sıcaklıkta kurutması sonucu, film negatiflerin emülsiyonları erimeye ve akmaya başlamış ve sonrasında toplamda yüz altı fotoğraftan sadece sekizi kurtarılmıştır. Fotoğraflarının netlikten uzak bir görünüm olmasına rağmen, söz konusu hikayenin efsanevi, kahramanlık, cesaret ve fedakarlık bileşenlerini içeriyor olması nedeniyle hiçbir zaman sorgulanmamıştır (Bakınız Şekil 4).

19. yüzyıl Fransız ve İngiliz fotoğrafının öncülerinden 21.yüzyılda onları araştıran bilim insanlarına ve fotoğraf kuramcılarına kadar başlangıçta 'kusur' ve 'kaza' olarak nitelendirilen imgeler, çağdaş sanat ile birlikte yeni anlam ve felsefi düşüncenin bir sonucu olarak bilinçli kusur bağlamında yeniden sunulmaya başlanmıştır.

Robert Capa'nın, bilinçdışı olarak gelişen arşiv ve belgesel amaçlı kusurlu savaş fotoğraflarına karşın, Alman sanatçı Gerhard Richter kusurlu ve bulanık görüntüyü bilinçli bir şekilde çalışmalarına yansıtmıştır. Sanatçı, izleyicinin zihnindeki düşleri betimleme yerine ideolojik imgeleri güdümleyici bir şekilde hatırlatması Hopkins'e $(2018$, s. 290) göre "son zamanların resim sanatının önemli bir figürü olan Richter'in artık bununla sıkı bir bağı olduğu ve daha da önemlisi Richter'in sürekli geliştirmekte olduğu arşivsel görüntülerle hem kişisel hem de toplumsal belleği akla getirmektedir". Sanatçı, bu söylemi ile fotoğraf sanatının yeni bir döneme geçtiğini vurgulamakta ve fotoğraf ve resim sanatı arsındaki 'tereddüt' hissini tema edinmişçesine yapıtlarında odaklanmamışlık etkisi yakalamak üzere görüntülerin dış hatlarını bulandırarak fotoğrafların boyanmış benzerlerini üretmiş ve fotoğrafı andıran resim değil, fotoğraf üreten sorgulama biçimleri gerçekleştirmiştir (Bakınız Şekil 5). 


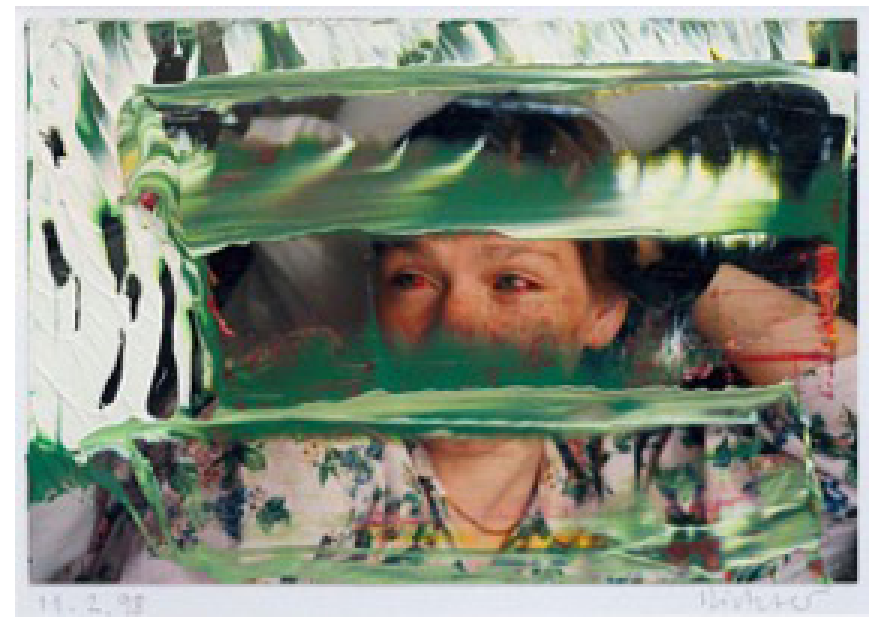

Şekil 5.İsimsiz, G. Richter, 1998
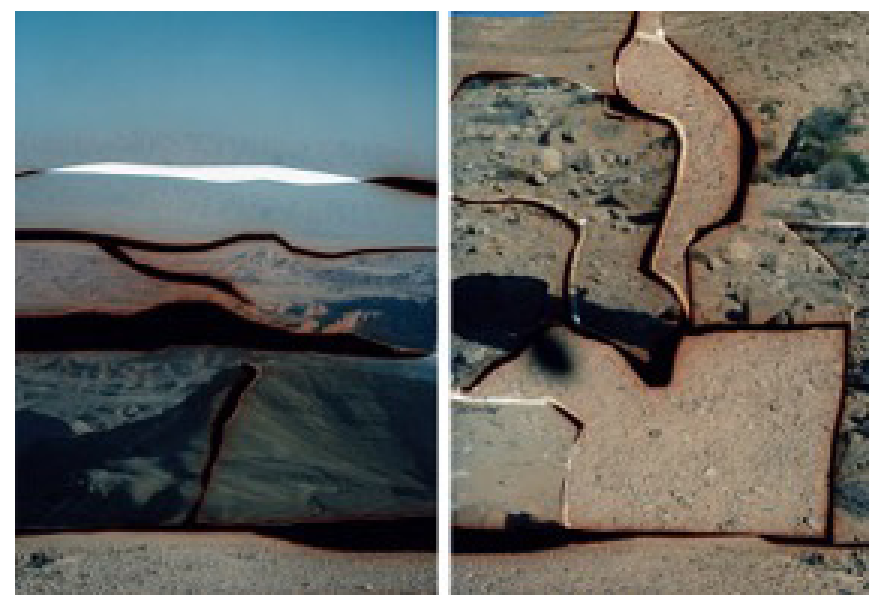

Şekil 6. Constracted Landcapes, D. Talmor, 2017

Fotoğraf, çağdaş bir sanat olarak, 21. yüzyıldaki çağdaş sanat düşüncesinden, dijital teknolojiden ve yeni medya uygulamalarından oldukça etkilenmiştir. Ancak aynı zamanda çağdaş fotoğraf sanatçıları 19 ve 20. yüzyılın geleneksel yöntemlerine ve araçlarına ilgi duymuşlar ve sıklıkla çalışmalarında bu dönemin özellikle avangard deneyselliğinden yararlanarak fotografik materyal üzerine müdahalelerde bulunmuşlardır.

Manzara, portre ve soyutlama çağdaş fotoğraf sanatçıların deneysel yaklaşımlarının ana temalarını oluşturmaktadır. Sanatçılar, bu ana temaları film yüzeyini renklendirme, özel madde karışımlarıyla bozma, lekeleme, fotoğraf kağıdının yüzeyini kazıma, sıyırma gibi yöntemlerle görüntüyü kusurlu hale dönüştürerek, Danto'nun (2010, s. 38) belirttiği gibi, 1970'li yıllarda ortaya çıkan, yerleşik bir anlam ve kimliğe sahip imgenin yepyeni bir anlam ve kimlikle sunulması bağlamında değerlendirmişlerdir.

İngiliz sanatçı Dafna Talmor, Venezüella, İsrail, İngiltere ve Amerika gibi ülkelerde çektiği negatif filmleri kesip bir araya getirmiş, aslında dünyada var olmayan ancak gerçekte yerleşik bir alan yaratmak için oluşturmuş olduğu 'Yapılı Manzaralar' serisinde hem doğrudan hem de karmaşık katmanlarda bir görüşü tasvir etmenin zor görevini üstlenmiştir. Bir araya getirilerek yeniden inşa edilen kusurlu manzara imgesi, yer, zaman ve doğa anlayışımızdaki yeri hakkında direnç göstererek sorgulanır hale gelmiştir (Bakınız Şekil 6).

Talmor, bu seriyi bir araya gelebilmesi mümkün olmayan veya birleşmeyecek tonlardan oluşturularak kesilmiş, parçalanmış ve bantlanarak bir araya getirilmiş negatifleri üst üste koyarak oluşturmuştur. Üst üste binen kısımlarından kaynaklanan beyaz parlak alanlar ile bazen hem derin hem de geçilmez gibi görünen siyah alanlar, Kertész'in Kırk Levha adlı çalışmasını anımsatmaktadır. Talmor'un projesinin ana nesnesi olan birleştirilmiş negatif filmler, somut ve okunaklı bir şekilde geleneksel manzara fotoğrafı hakkındaki görüşümüzü tam olarak yansıtmamasına karşın bir tanımlayıcı olarak peyzajdan ne anladığımızı tam olarak sorgulayan çalışmalardır. Shore’a (2017, s. 13) göre; “Talmor’un amacının görüntüyü belirli bir yere bağlı kalmadan, izleyicinin kendi duygularını yansıtması için yeni bir alan yaratmak düşüncesi ile hareket ettiğini” belirtmektedir.

'Yapılı Manzaralar', fotoğraf tarihi sürecinde önemli bir yeri olan resimselcilik tavrın yanı sıra modernist deneyimlere de gönderme yapmaktadır. Bu çalışmalar bir yandan geleneksel manzara fotoğrafı referanslarını belirgin bir şekilde tartışmaya açarken diğer yandan gerçek-düş ya da analog-dijital gibi temel unsurlara da yeni söylemler sunmaktadır.

Amerikalı sanatçı Alison Rossiter, rastlantı sonucu karanlık odada süresi geçmiş fotoğraf kâğıdı kullanarak gerçekleştirmiş olduğu çalışmalarında ışığa duyarlı gümüş tanecikli kağıt üzerinde bozulma ve kusurlar olduğunu saptamıştır.

Bu bağlamda fotoğrafik malzemeye başka bir gözle bakan Rossiter, tarihi geçmiş (1918-1946) kusurlu fotoğraf kâğıdı kullanarak, ışığa duyarlı gümüş tanecikli kağıt üzerinden zaman kavramını sorgulayan soyut çalışmalar gerçekleştirmiş ve kullanım tarihi geçmiş fotografik yüzeyde bugünü 
aramıştır. Alison Rossiter'in yapmış olduğu soyutlamalar gerçekte Mitchel'in (1989, s. 354) belirttiği gibi; “Clement Grenberg'in figüratif olanı yok sayan ve soyut sanatın dille olan ilişkisinden arınma düşüncesini reddeden” çalışmalar olarak değerlendirilebilir (Bakınız Şekil 7).

Amerikalı sanatçı Charles Grogg, yeniden yapılandırarak gerçekleştirdiği çalışmalarının merkezinde Japon gampi kağıdına basılmış ve ipliklerle dikilmiş dokunsal görüntüler yer almaktadır. Sanatçı, fotoğraflarında gerçek olmayan kurgusal hikayelere yer vermiştir. Grogg, yeniden yapılanmaların her bir parçasını ortaya çıkarmakla bütünlük eksikliğini bir düzeyde göstermek amacı gütmektedir. Manzara fotoğraflarında imgeleri raptiyeler, bantlar, zımbalar, tutkal ve iplikler kullanarak bir araya getirme yollarını deneyen Grogg, bu çalışmasında iğne ile görüntü yüzeyini delme hissi ve hareketini bir oyun düzeninde kullanarak bozulmuş olan doğayı bir araya getirmiştir (Bakınız Şekil 8).

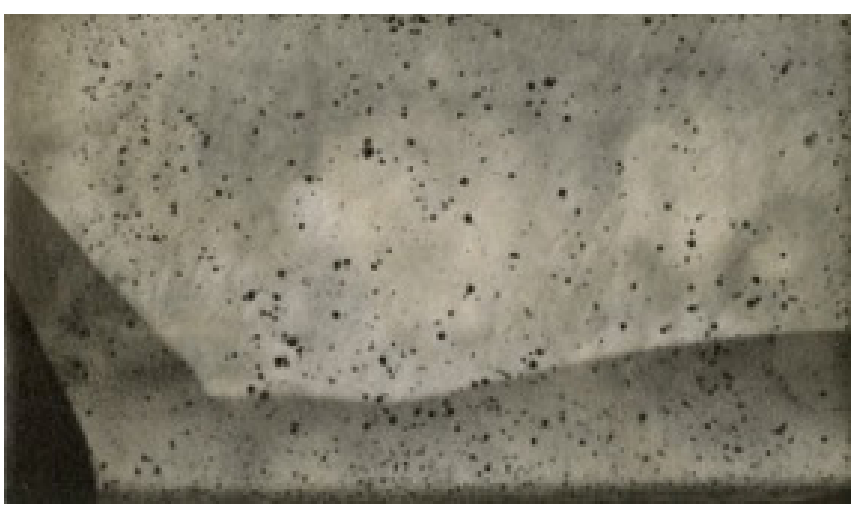

Şekil 7. Discovery Award, A.Rossiter, 2013

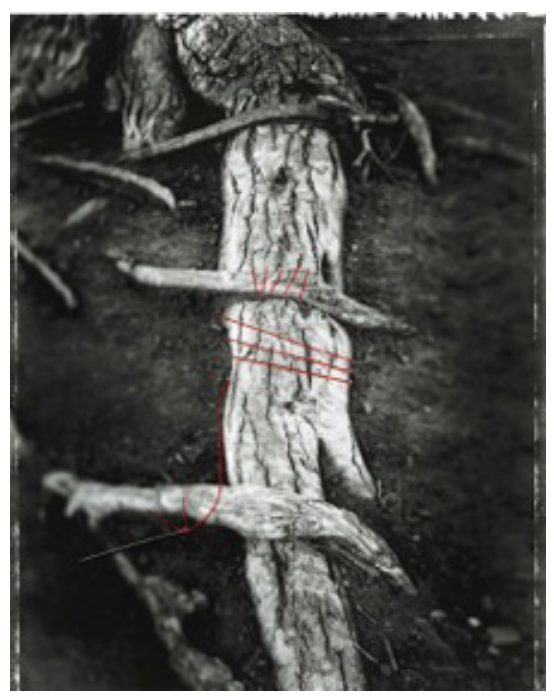

Şekil 8. After Ascenion and Descent, C. Grogg, 2010
Grogg'un fotoğraflarında endişe, bağlılık ve ölüm gibi temalar sıklıkla rastlanan kavramlardır. Bu amaçla fotoğrafları dikme, çamur, balmumu ve diğer malzemelerle bozan sanatçı, Higgins’e (2018, s. 7) göre “imgenin özünü ve düşüncelerini başka bir yere götürmeye zorlayan şeyi yine fotoğrafik yüzeyde aramaktadır”. Bağlama yöntemi, Grogg’un çalışmalarında görüntü yüzeyindeki gerilimi ve dehşeti ortaya çıkarmak için yaratılan ve tekrarlanan bir motiftir.

İngiliz sanatçı Catherine Yass, filmler üzerinde yapmış olduğu müdahaleler ve parlak renkli fotoğraflarıyla dikkat çekmektedir. Sanatçının çalışmaları genellikle olumlu ve olumsuzluğun bir birleşimi olan görüntülerden oluşmaktadır. Eserlerinin çoğu ışıklı kutulara monte edilmiştir. Bina görüntülerini yakma ya da parçalama etkisiyle yok eden Yass, geleneksel gelişim sürecini ortadan kaldırır ve fotoğraf filmini konuya uygun olarak ele alır.

Catherine Yass, fotoğraflarını, yıkım alanlarının etrafına, kirişlerin altına ya da cam ve moloz yığınlarına, kanallara, kanalizasyonlara, parklara ve hatta ayakkabı altına yerleştirerek yıpratmış ve doğaya, mimari yapılara ve çevreye verilen tahribatı zaman aşımı üzerinden eleştirmiştir. Böylece emülsiyon üzerinde çizik ve yırtılmadan kaynaklanan görüntü bozulmalarını daha sonra mekana ve izleyiciye göre değişen yüksekliklerde ışık kutularında konumlandırılmıştır. Bu çalışmalar, Yass'ın hayal gücü ve hafıza ile aydınlatılan geçmiş ve iç dünyaya açılan küçük pencerelerini anımsatmaktadır (Bakınız Şekil 9).

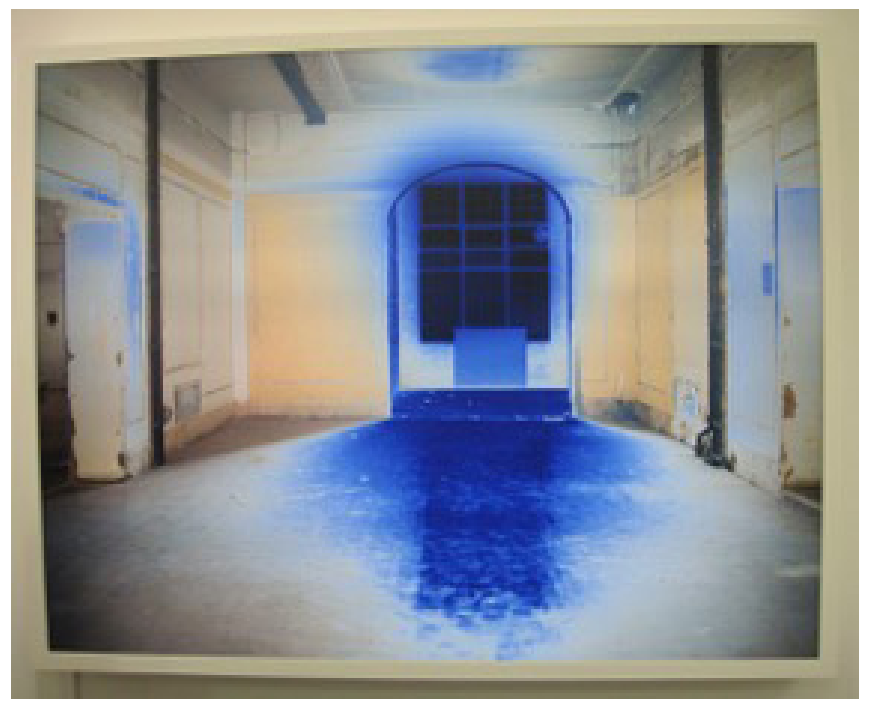

Şekil 9. JCC: Showroom, C. Yass, 2010 


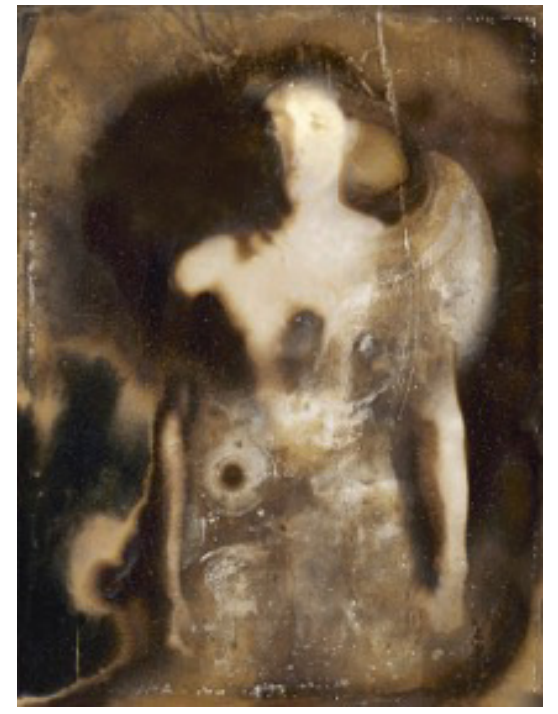

Şekil 10. Grace and Truth, L. Folino, 2017

Son otuz yıldır sadece Polaroid filmi ile çalışan Liso Folino, fotografik süreçte kusur ve kazalara çalışmalarında yer veren bir sanatçıdır. Stüdyosunda çalışırken kaza sonucu Polaroid film üzerine kimyasallar dökmüştür. Hasar gördüğü düşüncesi ile bu filmleri çöpe atan sanatçı ertesi gün tesadüf eseri bu filmlerin yüzeyinde bozulmalar görmüştür. Ağır hasar oluşan bu filmleri tekrar geri aldığında bu çalışmalarla ilgili düşüncesini uygulamaya karar vermiştir.

Bir ömür boyu fotoğrafik yüzeyin altında neyin var olduğunu keşfetme arzusu ile Unutulmuş ‘Forgotten' serisini gerçekleştirmiştir. Yedi yıl özel karışımlı kimyasal çözeltiler içinde beklettiği serisi ile sanatçı, fiziksel ve metaforik dönüşümün etkileri ile zaman, bellek ve değişim karmaşıklığı üzerine bir araştırma gerçekleştirmiştir (Bakınız Şekil 10).

\section{Dijital Çağda Kusurlu Fotoğraf}

David Birkin'in genellikle bilgisayar tabanlı manipülasyon ile gerçekleştirdiği çalışmalarının konusu savaş ve kayıp ile ilgilidir. 2004'te Afganistan'a bir gazeteci ile bir dizi röportaj yapmak için giden Birkin, orada yaşanan olayların çarpıtıldığına ve medyanın nasıl sansürlediğine tanıklık etmiştir.

Her zaman Don McCullen ve Philip Jones Griffiths gibi savaş fotoğrafçılarının çalışmalarından ilham almış olmasına rağmen, bir foto muhabiri olmak istemeyen Birkin, Susan Sontag'ın estetikleştirilmiş acı kavramı üzerinden izleyiciye karmaşadan kaynaklanan bozulmanın yanı sıra savaş ve kaybın etkilerini dile getirmenin bir yolunu bulmaya çalışmıştır.
Gömülü 'Embedded' serisinde Birkin, teknolojiyi insan ve bilgisayar arasında bir dil uyuşmazlığı yaratmak için bilerek işlevsiz bir şekilde kullanmış ve dijital kodlama işlemini kasıtlı olarak bozmuştur. Serideki her bir parça, birbirine çerçeveli bir çift baskıdan oluşur; biri fotoğraf, diğeri metin içerir. Birkin, sağdaki çerçeveyi kodlanmış JPEG format, soldaki çerçeveyi ise kusurlu görüntüyü üretmek için kullanmıştır.

Birkin, ‘Gömülü’ çalışmasında, 1966'da Nagasaki’nin bombalanmasının fotoğrafını çeken ve radyasyon zehirlenmesi sonucu kanserden ölen Yosuke Yamahata'nın adını kendi fotoğrafının dijital koduna yerleştirerek tekrar görsel hale getirmiştir. Sanatçı, burada 1945 yılında yürürlüğe giren "doğrudan veya manipülasyon yaratacak bilgi ile halkın huzurunu bozabilecek hiçbir şey basılmayacağını” (Birkin, 2011) öngörüsünü eleştiren bir yaklaşım sunmaktadır (Bakınız Şekil 11).

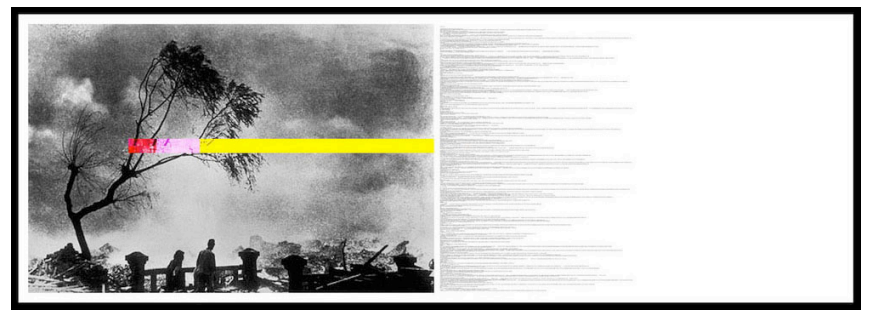

Şekil 11. Embedded, D. Birkin, 2011

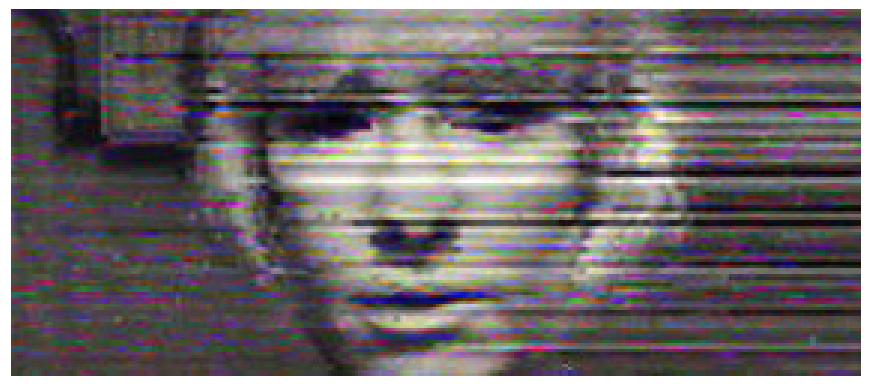

Şekil 12. Vernacular of File Formats, R. Menkman, 2011a

Rosa Menkman (2011b, s. 11), aksaklık sanatına ilham veren 'Glitch Moment(um)' manifestosunda Glitch sanatın kemikleşmiş tasarımlar uygulamalarına daha fazla dikkat çekmek için standartlaştırılmış sistemlere karşı bir dosya formatı geliştirmiştir. Menkman, çalışmalarında, mesajların nasıl oluşturulduğu, iletildiği, alındığı ve gürültünün bu yayınların içine nasıl girdiğini anlamak için, Claude Shannon'un yazıları aracılığıyla iletişim teorisinin kökenlerini 
araştırarak, gürültü ve aksaklık sanatına bilimsel bir yaklaşım getirmiştir. Bu yaklaşım sanatçıların, görüntü formatlarını, sıkıştırma yapılarını sistematik olarak ele alınmasına, veri tabanlarını nasıl değiştirebileceklerine yönelik çeşitli teorik ve tarihsel yaklaşımları yanı sıra kendi bilgisayar korsanlık süreçlerini genişletmelerini sağlamak için tasarlanan bir programdır.

Glitch sanatçıları kazanın akışını, imajını ve bilgi boşluğundan faydalanarak şifre çözme için alan yaratan bilgi eksikliği ile yeni tür anlam yaratma sürecini yorumlamışlar ve göz kamaştırıcı desenlerin estetik yapısı ve piksellerin yönlendirilmesi yoluyla yeni ifade biçimleri geliştirmişledir. Böylece aksaklık sanatçıları makine tekniği ile duyusal deneyim sağlamışlardır.

Menkman, 2011 yılında Johan Larsby ile birlikte kullanıcının tamamen kolayca kod yazmasını sağlayan bir aksaklık yazılımı olan Monglot'u geliştirmiştir. Monglot yazılımı sıkıştırılmış aksak görüntüleri görsel bir dil oluşturmak için bir araya getirerek oluşturulan bir yazılım şeklidir. Bu yazılım ile harap olan görüntü üzerinde 'parçalanma', 'gölgeleme', 'birleştirme', 'solarizasyon', 'pixselleştirme' ve benzeri uygulamalar yapılmaktadır (Bakınız Şekil 12). Ayrıca yazılım, hangi tür baskıların belirli türlerde estetik sonuçlara yol açabileceği hakkında kullanıcının bilgilerinin arttırmasını da sağlamaktadır.

Monglot, sanatçıları kod, yazılım ve kavramlarla oynamaya davet eden açık kaynaklı görüntü oluşturma araçlarıdır. Monglot, görüntü dosyalarını geleneksel bir standarttan diğerine dönüştürür ve bir bilgi düzeyinde görüntüleri veri tabanlarına aktararak biçimleri ve karşılık gelen hataların metalaştırılmasını eleştirmiştir. Böylece görüntü estetiğine odaklanan araştırma ve aksaklık tasarımı amaçlanmıştır.

\section{Sonuç}

Sosyal medya kullanıcıları, amatör fotoğrafçılar, basın, sanat galerileri, çağdaş sanatçıların fotoğrafa olan ilgisi giderek artmakta ve bunun sonucunda yoğun bir imge doygunluğu yaşanmaktadır. Ancak, imge doygunluğu yaşayan dünyamızın içinde bulunduğu zorluk tüm bu imgelerle ne yapılması gerekliliğidir. Bu amaçla kimi fotoğrafçılar ve sanatçılar çalışmalarında hatalı ya da kusurlu görüntü olarak kabul edilen imgeler kullanarak yeni anlatılar geliştirmişlerdir.

Görüntüler önemli yüzeylerdir. Fotoğraf tarihi boyunca bu yüzeylerde farklı anlatılar gerçekleştirilmiştir. Kimi zaman bu yüzeyler bir belge ve arşiv, kimi zaman soyutlama, portre ya da deneysel kimi zaman kavramsal bağlamlarda yer almış ve bu yüzeydeki görüntülerle hayal gücünün sınırları genişletilmiştir.

Bir yandan anolog, diğer yandan dijital çağın gereği ortaya çıkan kusurlu görüntüler, anlam üretim biçimlerin yeni stratejilerini oluşturmuştur. Böylece başlangıçta kusurlu olarak nitelendirilen görüntü, fotoğraf sanatının geleneksel estetik kurallarının dışına çıkarak bilinçli kusur bağlamında yeniden tasvir edilmiştir.

Yeniden tasvir edilen kusurlu görüntü ister fotoğrafik malzeme özelliğinden isterse sanatçının öznel tavrından kaynaklansın izleyiciden ortaya konulan bu yeni yaklaşımları sorgulanması istenmiştir.

Sonuç olarak, 19. yüzyılın sonlarında geleneksel bakış açısının yıkılması ile başlayan ve son otuz yılda radikal bir şekilde fotoğrafın büyülü dünyasında yeni bir anlatı olarak karşımıza çıkan kusurlu görüntüler, hem analog hem de dijital sanatın biçim, anlatım ve kültürünü etkileyen temel unsurlarından biri olmuştur.

\section{Kaynakça}

Birkin, D.(2011). Embedded [Dijital baskı]. Retrieved from: https://www.davidbirkin.net/art\#/embedded/

Capa, R.(1944). D-Day [Jelatin gümüş baskı]. Retrieved from: https://www.magnumphotos.com/newsroom/conflict/ robert-capa-d-day-omaha-beach/

Danto, A. C. . (2010). Sanatın sonundan sonra(Z. Demirsu, Çev.), İstanbul: Ayrıntı Yay.

Folino, L. (2017). Grace and Truth [Jelatin gümüş baskı]. Retrieved from: https://www.celesteprize.com/artwork/ido:198052/

Friedlander, J. (2008). Affecting art: Barthes, Kertesz and Lacan. (Re)-turn: A Journal of Lacanian Studies, Volume 3 \& 4 , Spring, 151-172. Retrieved from: https://return.jls.missouri. edu/ReturnVol3_4/friedlander.pdf

Grogg, C. (2010). After Ascension and Descent [Jelatin gümüş baskı]. Retrieved from: https://neworleansphotoalliance. org/grant-recipients/after-ascension-and-descent/12 grogg_charles_subterraneous2_550/

Higgins, J. (2014). Fotoğraf neden kusursuz olmak zorunda değildir (F. Candil Çulcu, Çev.). İstanbul: Hayalperest Yay. 
Hopkins, D. (2018). Modern sanattan sonra (F. Candil Erdoğan, Çev.). İstanbul: Hayalperest Yay.

Kertesz, A. (1929). Broken Plate [Jelatin gümüş baskı]. Retrieved from: https://www.ngv.vic.gov.au/explore/collection/ work/8390/

Martin, J.H.(1997). Man Ray photographs. New York: Thames and Hudson.

Menkman, R. (2011a). The Glitch moment(um), Network Notebook Series. Amsterdam: Institute of Network Cultures.

(2011b). Vernacular of File Formats [Dijital baskı]. Retrieved from: http://digicult.it/articles/the-punctum-as-glitch-incontemporary-art/

Mitchell, W. J. (1989). “ Ut Pictura Theoria”: Abstract Painting and the Repression of Language. Critical Inquiry, 15(2), 348371.

Ray, M. (1935). Partial Solarization [Jelatin gümüş baskı]. Retrieved from: https://smartartbox.com/blogs/smart-artblog/the-modernist-lens-man-ray-and-the-photogram

Richter, C. (1988). İsimsiz [Jelatin gümüş baskı]. Retrieved from: https://images.squarespace-cdn. com/content/v1/5a3410388dd041 ba976f6e 0e/1556551039141-AT0K7ZUH094SX5I5RI74/ke $17 Z$ wdGBToddI 8 pDm 48 kNesHe1WGjhsIru0Q6zOM $3 V Z w-z P P g d n 4 j U w V c J E 1 Z v W Q U x w k m$ yExgINqGp0 IVTJZUJFbgE-7XRK3dMEBRBhUpwFBGsWTVbFkw vGoXMeb9PXuww7wJ8JESwER0zM7Vm0XTzjjcha9xDZ ZZUuzZ_dc/GR_OP_2.jpg?format $=750 \mathrm{w}$

Rossiter, A. (2013). Discovery Award [Jelatin gümüş baskı]. Retrieved from: https://loeildelaphotographie.com/wpcontent/uploads/2013/06/original_2013-ros-cat08-1-11jpg.jpg

Shore, R. (2017). Post-photography:The Unknown image. Retrieved from: http://elephant.art/post-photographyunknown-image/

Steidl, K. (2011). Traces of / by nature: August Strindberg's photographic experiments of the 1890's. Retrieved from: http://www.iwm.at/iwmauthor

Strindberg, A.(1890). Celestograph [Jelatin gümüş baskı]. Retrieved from: https://publicdomainreview.org/collection/ august-strindberg-s-celestographs-1893-4/

Talmor, D. (2017). Constracted Landcapes [Jelatin gümüş baskı]. Retrieved from: https://www.photofusion.org/_/wp/wpcontent/uploads/2017/01/Dafna-Talmor-Website.jpg

Virilio, P. (2016). Sanat kazası (N. Türk, Çev.). İstanbul: Corpus Yayınları.
Yass, C. (2010). JCC: Showroom [Jelatin gümüş baskı]. Retrieved from: https://thewomensroom.typepad.com/.a/6a0105356c 398f970c0133f50b8099970b-pi 